\author{
Marquette University \\ e-Publications@Marquette
}

College of Nursing Faculty Research and

Publications

Nursing, College of

2017

\title{
Answering Wicked Questions: Dealing With Opposing Truths as a Nursing Associate Professor
}

Robert V. Topp

University of San Diego

Patricia E. Hershberger

The University of Illinois at Chicago

Marilyn Bratt

Marquette University, marilyn.bratt@marquette.edu

Follow this and additional works at: https://epublications.marquette.edu/nursing_fac

Part of the Nursing Commons

\section{Recommended Citation}

Topp, Robert V.; Hershberger, Patricia E.; and Bratt, Marilyn, "Answering Wicked Questions: Dealing With Opposing Truths as a Nursing Associate Professor" (2017). College of Nursing Faculty Research and Publications. 563.

https://epublications.marquette.edu/nursing_fac/563 
Marquette University

e-Publications@Marquette

\title{
Nursing Faculty Research and Publications/College of Nursing
}

This paper is NOT THE PUBLISHED VERSION; but the author's final, peer-reviewed manuscript. The published version may be accessed by following the link in the citation below.

Western Journal of Nursing Research, Vol. 39, No. 6 (Junw 1, 2017): 733-744. DOI. This article is (C) SAGE Publications and permission has been granted for this version to appear in e-

Publications@Marquette. SAGE Publications does not grant permission for this article to be further copied/distributed or hosted elsewhere without the express permission from SAGE Publications.

\section{Answering Wicked Questions: Dealing With Opposing Truths as a Nursing Associate Professor}

Robert Topp

University of San Diego, San Diego, CA, Patricia E. Hershberger

University of Illinois at Chicago, Chicago, IL

Marilyn Bratt

Marquette University, Milwaukee, WI

\begin{abstract}
Nursing associate professors frequently are confronted with increasing responsibilities and fewer resources. These challenges commonly contribute to declines in job satisfaction and may result in departing academe. This article addresses these challenges by providing answers to four common "wicked questions" experienced by nursing associate professors: (a) How do I decline a request from a supervisor to take on additional responsibilities while continuing to support the mission of the school
\end{abstract}


and advance my own scholarly productivity? (b) How do I handle the workload of multiple doctoral students with a variety of content areas that are different from my own and maintain my own level of productivity? (c) How do I handle expectations for more service, and leadership for the school, university, and professional organizations, yet the teaching and research responsibilities have not changed or have increased? and (d) What are some additional tips to being a more productive nursing associate professor?

Recent national data show that associate professors report the highest levels of career unhappiness among people in academe (Wilson, 2012). Life as an associate professor with tenure even can be more isolating and overwhelming than being an assistant professor on the tenure track. Research indicates that associate professors are significantly less satisfied with their work compared with either assistant or full professors (Jaschik, 2012). The path to achieving tenure and promotion to associate professor commonly includes intramural support and guidance from more seasoned peers. Once a faculty member achieves the rank of associate professor, that support and guidance commonly dissipates. As an associate professor, the amount of service, committee work, and leadership responsibilities commonly increase (Baldwin, Lunceford, \& Vanderlinden, 2005), whereas the expectations for teaching and research remain the same or increase (Strage \& Merdinger, 2015). This article will identify challenges and approaches that recently promoted nursing associate professors frequently experience and will be addressed through answering four common "wicked questions."

A wicked question is based on the term wicked problem which has been defined as a social or cultural problem that is difficult or impossible to solve (Rittel \& Webber, 1973). In contrast, a wicked question contains contradictory role expectations that are difficult or impossible to achieve simultaneously. Wicked questions that confront nursing associate professors involve maintaining scholarly productivity with fewer resources, increased service expectations, more student advising, and more committee responsibilities while experiencing less support when compared with earlier career expectations. Exploring wicked questions allows the paradoxes inherent in these questions to be transparent and supports constructive approaches to addressing these questions. Furthermore, exploring responses to wicked questions may facilitate job satisfaction and scholarly productivity among nursing associate professors. This article identifies four common wicked questions that confront nursing associate professors and explores constructive responses to these questions. These wicked questions and responses resulted from the presentations and discussions during a session titled Answering Wicked Questions: Dealing With Opposing Truths as an Associate Professor presented at the 2016 Midwest Nursing Research Society (MNRS) Conference.

Wicked Question 1: How do I decline a request from my supervisor to take on additional responsibilities while continuing to support the mission of the school and advance my own scholarly productivity? In other words, what are some strategies to saying "no" to my boss and not appear insubordinate?

This is not a unique wicked question in academia, particularly for those in academic nursing. As the shortage of nursing faculty continues (American Association of Colleges of Nursing, 2015), in addition to budget reductions in academia, nursing associate professors are being asked by their supervisors to 
take on more responsibilities with fewer resources (Nottis, 2005). When addressing this wicked question, the content of the response as well as its delivery to one's supervisor must be considered.

Developing the content of a response to this question includes a number of considerations. When asked to take on additional responsibilities, it is best to avoid directly declining your supervisor's request. If you respond by saying "no," you may be perceived as questioning your supervisor's ability, competency, and/or judgment, thus setting up a power struggle in a relationship in which you are the one with limited power. Also, avoid responding immediately if not necessary. This "pause" in responding mitigates an emotional reply and minimizes the possibility of a visceral rather than a contemplative response (Davidds, 2015). Very few issues in academia require an immediate response, so take advantage of thinking through the implications of several different answers. Finally, do your homework. Attempt to understand why your supervisor is making the request. It may be that the request is a result of a mandate from a more senior-level administrator or the result of personal or professional challenges being experienced by another faculty member that necessitates a shifting of workload responsibilities. This knowledge will assist you in formulating the content and delivery of your response.

When developing your response, begin by recognizing and empathizing with your supervisor's position and how the advancement of the mission of the unit, rather than your individual agenda, is everyone's first priority. Supervisors rarely ask individuals to take on additional responsibilities without considering the impact of their request on the individual as well as the entire unit's productivity. An effective response to this type of request includes generating alternative solutions while providing rationale for the alternatives. Approaching a supervisor with a problem and no solutions can be viewed as complaining. However, approaching a supervisor with a problem and a variety of solutions with corresponding rationale can be viewed as participating in finding an effective resolution of the problem. When presenting alternative solutions, also present relevant financial implications and how a solution will affect the workload of other personnel. Shifting a request for additional responsibilities to another overburdened faculty member without discussing his or her role in the solution is not likely to build cohesiveness among faculty and minimizes the importance of another faculty member's individual scholarly activities. Thus, responding to a supervisor's request to take on additional responsibilities needs to include alternative solutions and rationale that advance the mission of the unit without dramatic financial expenditures or shifting of work responsibilities, while preserving your individual productivity.

The delivery of the response to this question is equally as important as the content of the response. Again, avoid being confrontational. A confrontational response is not as effective as a collaborative response (Losa Iglesias \& Becerro de Bengoa Vallejo, 2012). Explain your perceptions of the implications of the request, such as how will fulfilling the request affect not only your productivity but also that of the unit and how various alternatives can maintain or improve the productivity of the entire unit.

When considering the delivery of your response, timing may be a critical component. Be aware of competing priorities that your supervisor may be addressing when you respond to the request. Communicate your concerns to your supervisor in a private setting rather than in a public forum that may result in your approach being perceived as argumentative, insubordinate, or insignificant. Do not 
ask for an immediate decision to your response as your supervisor will need to contemplate the implications of the alternatives you present. Ask your supervisor to determine the medium through which further discussion can occur, be that a face-to-face meeting, memo, email, or in a forum with others who may be affected by any decisions being considered. Being mindful of these approaches to delivering your response increases the probability that your supervisor will consider your alternatives rather than assigning you more responsibilities with perhaps fewer resources.

A few other areas need to be considered when addressing this wicked question. First, do not state dire consequences of complying with these additional workload requests as this undermines your supervisor's competency. Instead, offer alternative solutions that will accomplish or exceed the unit's objectives. Second, establish a mutual understanding about the scope and time commitment of the request to avoid "mission creep" or expansion of the request beyond its original goals. The best approach to establishing a mutual understanding with your supervisor is to write down and share how you perceive your involvement in the request and how fulfilling this request will affect your other responsibilities. Finally, seek the counsel of a mentor who can advise you on the content and delivery of your response to your supervisor's request. This mentor may offer you insights into the rationale of your supervisor's request and the plausibility of your alternative solutions.

Wicked Question 2: How do I handle the workload of multiple doctoral students with a variety of content areas that are different from my own and maintain my own level of productivity?

The shortage of nursing faculty mentioned previously often necessitates the assignment of doctoral student to newly promoted associate professors. This responsibility requires overseeing students' program progression, supervising their dissertation, grant proposal submissions, as well as mentoring them in the writing of abstracts and manuscripts. Supervising doctoral students also can take time away from your own research, thereby decreasing your scholarly productivity, which has been found to predict faculty turnover (Yedidia, Chou, Brownlee, Flynn, \& Tanner, 2014). Lack of alignment between your program of research and your doctoral student's dissertation research can exponentially increase your workload. This increase in workload has been identified as a key factor driving nursing faculty to leave their positions (Tourangeau, Wong, Saari, \& Patterson, 2015).

Addressing this wicked question can begin while you are an assistant professor. Assistant professors typically are focused on their own scholarly productivity which can preclude taking advantage of opportunities to work with doctoral students. Before taking on the role of associate professor, it is helpful to first serve as a member of a dissertation committee in your area of expertise, which is led by an experienced peer. Being a member of a dissertation committee as an assistant professor also can help you identify future collaborators (students and faculty) who may contribute to your area of research. Serving on a dissertation committee as an assistant professor also is an opportunity to build relationships with faculty mentors who can guide you through the tenure process.

Once achieving promotion to nursing associate professor you need to carefully review expectations of your new rank. These new expectations usually includes working with doctoral student to foster their academic progression. As part of this process, review your institution's dissertation guidelines and dissertation committee roles and responsibilities, and review the workload policies that govern your 
academic unit. Early on, arrange a meeting with your dean or supervisor to clarify expectations regarding your level of involvement with doctoral students. You need to reach a consensus with your supervisor regarding the number of dissertation committees you are expected to participate on and in what capacity, as the chair or a committee member. Prior to this meeting, it is critical to identify how your participation on a dissertation committee will accelerate and/or inhibit your own research trajectory. Identifying the positive and negative impact on your scholarly productivity, as a result of serving on dissertation committees, will help to determine a reasonable workload that benefits both your scholarship and the academic progress of your doctoral students.

Another approach to this wicked question is to advocate for coalescence among areas of faculty research and actively recruit doctoral students who share an interest in these areas. As a nursing associate professor, take an active interest in recruiting doctoral students whose research interests closely align with your respective area of research expertise. Be involved in interviewing prospective doctoral students and encourage acceptance of students who express an interest in areas of research that are congruent with those of your faculty.

In many cases, it is not feasible to have alignment between faculty' and doctoral students' research, which requires other strategies to address the doctoral student's needs as well as preserve your scholarly productivity. Therefore, in the event you are assigned to advise a student whose research interest is dissimilar to yours, attempt to "reshape" the student's interest to be compatible with your own. Begin this dialogue by establishing your mutual goal, which is that the student successfully moves through the phases of their doctoral education in a timely fashion. Explain to the student that this goal is best accomplished if there is scholarly synergy between the two of you. Outline your current program of research and methodologic expertise and attempt to find some common ground. Convey that redirecting toward a more complementary research trajectory will foster collaborative work that more effectively advances the science and ultimately will expedite the student's progress.

If your doctoral student is resolute in pursuing a scholarly area disparate from yours, then you will need to enlist the participation of other faculty who can support the student's intended area of research. The student needs to be actively involved in the process of identifying scholars with appropriate expertise and who you deem as acceptable doctoral committee members. Supporting doctoral students' progress is a shared responsibility among the senior faculty. Therefore, engaging in a mindful strategic planning process among the senior faculty also can identify the necessary content expertise within or outside of the nursing faculty who could provide meaningful contributions to the student's work. Another approach is to explore the possibility of cochairing the student's doctoral committee with a peer, which can capitalize on both of your strengths and divide the workload.

Wicked Question 3: How do I handle expectations for more service, and leadership for the school, university, and professional organizations, yet the teaching and research responsibilities have not changed or have increased?

It is not surprising that many associate professors express concern about engaging in additional service activities following tenure and promotion. Indeed, in one of the few studies examining newly tenured scholars at universities in the United States, Neumann and Terosky (2007) found that $87 \%$ of participants indicated their service responsibilities increased after tenure. For some participants, the 
rise in service was gradual while others reported a quick and dramatic expansion in service posttenure.

There are several underlying issues to consider regarding "service" that can provide a foundation for insight into developing constructive approaches to navigating the service responsibilities by nursing associate professors. First, service is the third historic mission of universities, following both teaching and research missions. This has contributed to "service" being poorly defined, compared with teaching or research metrics, which contributes to service responsibilities being poorly rewarded in contemporary academia (Macfarlane, 2005, 2007). This nebulous definition of academic service (Ward, 2003) makes service efforts difficult to measure or quantify. Whereas with teaching, semester or quarterly hours taught or number of students supervised can be easily calculated. As well, research activity commonly is quantified as the number of publications, research grant awards, or funding dollars. For many academics, the view that service is less important than teaching or research is perpetuated by the wide-spread practice of assistant professors having limited service expectations.

Associate professors can implement constructive approaches to this wicked question through several strategies. First, proactively prepare for an anticipated increase in service activities following promotion. This preparation includes strategizing ways to engage numerous fellow faculty in the same service activity, thus leveraging the service activity to the benefit of many faculty. In addition to planning for an anticipated rise in service activities, Neumann and Terosky (2007) found that scholars should realistically plan for not only more service but also an intensification of the service that is performed. Intensification in service is the expectation that associate professors be leaders in service activities such as chairing or leading departmental and organizational committees or units.

By anticipating an increase in service following promotion to associate professor, a number of proactive strategies can be considered during one's early career. By participating in a wide range of committees and/or interfacing with multiple organizations, an assistant professor can begin to recognize synergistic service efforts that combine their teaching and research interests. As a result, associate professors can be better positioned to assume leadership service that also contributes to teaching and research efforts (e.g., serving as a journal editor in a substantive area, chairing a research or curriculum committee for the department or university, and directing graduate programs). For instance, a service trajectory within academia for nurse scholars with a focus on teaching could be to serve as a member of the nursing curriculum committee and eventually chair a subcommittee to implement new curriculum. As an example, participating in a regional organization such as the MNRS provides numerous opportunities to simultaneously contribute to growth as a researcher and manage teaching, service, and leadership responsibilities.

Early career assistant professors often begin service in MNRS by chairing a Research Interest Group (RIG) that aligns with their particular research interest (e.g., adolescent health, decision making, and qualitative methods). As a RIG chair, they may oversee a successful proposal for a special conference session, which can lead to service on the MNRS Program Planning Committee. Then progress to be appointed as the chair of this committee when promoted to associate professor. In both examples, as nurse scholars are actively serving on committees, they can gain valuable information about whether the work of the committee and future opportunities afforded by service on the respective committee will contribute to their teaching and research interests. 
Wicked Question 4: What are some additional tips to being a more productive associate professor?

From a global perspective, Baldwin and Chang (2006) presented a comprehensive model for midcareer faculty development comprised of three foundational elements: collegial support, resources, and reinforcement. These components support the processes of career reflection, assessment, planning, and implementation. Some of the specific strategies they identify include providing faculty with information and research resources, collegial support, and recognition programs.

As a focal strategy, to promote your role transition to associate professor, request that formal developmental support opportunities be implemented such as those outlined by Baldwin, DeZure, Shaw, and Moretto (2008). They suggest that there be ongoing workshops that include such topics as orientation to the experiences and expectations of newly tenured faculty, leadership development within the academic unit, and managing a grant. Mathews (2014) viewed this as "anticipatory guidance" as these types of workshops can address topics regarding the realities of one's new rank and provide strategies for longitudinal success as an associate professor. This forward-thinking approach can provide you with the next level of support to help you advance to full professor. This is particularly critical based on the results from the Collaborative on Academic Careers in Higher Education (COACHE) survey conducted between 2011 and 2014 that found that associate professors in their rank for more than 5 years are the least satisfied among academic levels within their academic unit (Mamiseishvili, Miller, \& Lee, 2016).

On a granular level, additional tips to being a more effective associate professor involves effective time management skills (Chase et al., 2013) as well as continual investment in self-development. Developing new skills in using innovative research and teaching tools will contribute to productivity and can maintain or improve cognitive functioning (Vemuri et al., 2014). Learning to use citation management software, Internet-based plagiarism screening software, and professional social media sites can contribute to increased productivity. Likewise, networking with other colleagues who are proficient in these skills or who can provide recommendations for resources also can enhance productivity.

Because the profession of nursing has historically been female dominated, attention to larger sociocultural issues that can affect women's professional careers is important. Notably, in 2006, representatives of the Committee on Maximizing the Potential of Women in Academic Science and Engineering set out to address how to make the most of the contributions of women in these professions (National Academy of Sciences, National Academy of Engineering, \& Institute of Medicine, 2006). In their groundbreaking report, the authors conclude that women are very likely to face discrimination in every field of science. The authors go on to say that women's social characteristics of flexibility, diplomacy, curiosity, motivation, and dedication-also hallmarks of the nursing professionare typically not as valued as assertiveness and single-mindedness, which are often given greater weight in the scientific community. Awareness of these barriers, and often the implicit bias held by both men and women that surrounds "women's work," can serve as a first step to circulating effective strategies (Glass, Sassler, Levitte, \& Michelmore, 2013). Yet, in a study examining why women in engineering stayed in the profession despite challenges of gender discrimination and/or harassment, investigators found that women who stayed often reported individual factors such as self-efficacy and 
confidence (Buse, Bilimoria, \& Perelli, 2013). Fostering the development of these individual characteristics may also be beneficial to associate professors of nursing.

Associate professors at midcareer can also be vulnerable to competing demands of career and life as children and child care, elders and elder care, and other personal issues may arise during the midpoint of an individual's career (Marcinkus, Whelan-Berry, \& Gordon, 2007). Nursing faculty can be particularly vulnerable to these conflicting demands because they may take on the responsibility as the "family's" designated caregiver and health care advocate.

Although time management and self-development are important skills, recognizing that your passion for your career can become obsessive, and hence hinder productivity, is an emerging area of study in organizational/employee work output (Ho \& Pollack, 2014; Ho, Wong, \& Lee, 2011; Perrewé, Hochwarter, Ferris, McAllister, \& Harris, 2014). Associate professors who have passion for their research and careers have likely dedicated an immense amount of time, resources, and energy to their work and may want to consider the importance of work-life balance. Planning and engaging in periods of cognitive and physical down-time to enhance productivity and mitigate burnout can be helpful to navigating academic career challenges (Keeton, Fenner, Johnson, \& Hayward, 2007).

Finally, mentoring is a crucial resource for all faculty, because without adequate mentoring, faculty have an increased potential to leave their institution (Kalet, Fletcher, Ferdman, \& Bickell, 2006). Furthermore, high quality mentoring during midcareer is particularly needed (Stubbs et al., 2016). Deploying a model of faculty group mentoring, as described by Pololi and Evans (2015), may be a viable method as it has been shown to increase faculty collaboration and development of their career goals. Maintaining a mentor can assist you to periodically reevaluate your professional goals and your progress toward those goals, which may result in modifying your plan and ultimately increase your productivity. As your academic career advances, also consider having a "network" of mentors. Although a strong and highly successful mentor is often an ideal situation, the mentor's career also may be advancing and moving toward a purposeful reduction in effort and productivity. Thus, establishing various mentors to provide guidance and networking, and to assist you to address challenges related to your teaching, research, or service, can be extremely beneficial.

With promotion to associate professor, nurses commonly experience an increase in professional responsibilities that are accompanied by fewer resources. These circumstances commonly manifest as "wicked questions," which are difficult to resolve. This article has presented answers to four of the more common wicked questions that associate professors face. These answers included strategies to address a supervisor's request to take on additional responsibilities, manage the additional challenges of working with doctoral students, and juggle increased expectations to lead service activities, and additional tips to enhance productivity such as professional development and career support activities, mentoring, and networking.

\section{References}

American Association of Colleges of Nursing. (2015, March 16). Nursing faculty shortage fact sheet. Retrieved from http://www.aacn.nche.edu/media-relations/facultyshortageFS.pdf Baldwin, R. G., Chang, D. (2006). Reinforcing our "keystone" faculty. Liberal Education, 92(4), 28-35. 
Baldwin, R. G., DeZure, D., Shaw, A., Moretto, K. (2008). Mapping the terrain of mid-career faculty at a research university: Implications for faculty and academic leaders. Change, 40(5), 46-55.

Baldwin, R. G., Lunceford, C. J., Vanderlinden, K. E. (2005). Faculty in the middle years: Illuminating an overlooked phase of academic life. The Review of Higher Education, 29, 97-118.

Buse, K., Bilimoria, D., Perelli, S. (2013). Why they stay: Women persisting in U.S. engineering careers. Career Development International, 18, 139-154.

Chase, J. A., Topp, R., Smith, C. E., Cohen, M. Z., Fahrenwald, N., Zerwic, J. J., . . Conn, V. S. (2013). Time management strategies for research productivity. Western Journal of Nursing Research, 35, 155-176. doi:10.1177/0193945912451163

Davidds, Y. (2015). Your own terms: A woman's guide to taking charge of any negotiation. New York, NY: AMACOM.

Glass, J. L., Sassler, S., Levitte, Y., Michelmore, K. M. (2013). What's so special about STEM? A comparison of women's retention in STEM and professional occupations. Social Forces, 92, 723-756.

Ho, V. T., Pollack, J. M. (2014). Passion isn't always a good thing: Examining entrepreneurs' network centrality and financial performance with a dualistic model of passion. Journal of Management Studies, 51, 433-459.

Ho, V. T., Wong, S. S., Lee, C. H. (2011). A tale of passion: Linking job passion and cognitive engagement to employee work performance. Journal of Management Studies, 48, 26-47.

Jaschik, S. (2012, June 4). Unhappy associate professors. Inside Higher Ed. Retrieved from https://www.insidehighered.com/news/2012/06/04/associate-professors-less-satisfiedthose-other-ranks-survey-finds

Kalet, A. L., Fletcher, K. E., Ferdman, D. J., Bickell, N. A. (2006). Defining, navigating, and negotiating success: The experiences of mid-career Robert Wood Johnson clinical scholar women. Journal of General Internal Medicine, 21, 920-925.

Keeton, K., Fenner, D. E., Johnson, T. R., Hayward, R. A. (2007). Predictors of physician career satisfaction, work-life balance, and burnout. Obstetrics \& Gynecology, 109, 949-955.

Losa Iglesias, E. M., Becerro de Bengoa Vallejo, R. (2012). Conflict resolution styles in the nursing profession. Contemporary Nurse, $43,73-80$.

Macfarlane, B. (2005). The disengaged academic: The retreat from citizenship. Higher Education Quarterly, 59, 296-312.

Macfarlane, B. (2007). The academic citizen: The virtue of service in university life. London, England: Routledge.

Mamiseishvili, K., Miller, M. T., Lee, D. (2016). Beyond teaching and research: Faculty perceptions of service roles at research universities. Innovative Higher Education, 41, 273-285.

Marcinkus, W. C., Whelan-Berry, K. S., Gordon, J. R. (2007). The relationship of social support to the workfamily balance and work outcomes of midlife women. Women in Management Review, 22, 86-111.

Mathews, K. R. (2014). Perspectives on midcareer faculty and advice for supporting them. Cambridge, MA: The Collaborative on Academic Careers in Higher Education. Retrieved from http://coache.gse.harvard.edu/files/gse-coache/files/coache-perspectives-on.pdf

National Academy of Sciences, National Academy of Engineering, \& Institute of Medicine . (2006). Beyond bias and barriers: Fulfilling the potential of women in academic science and engineering. Washington, DC: National Academies Press.

Neumann, A., Terosky, A. L. (2007). To give and to receive: Recently tenured professors' experiences of service in major research universities. The Journal of Higher Education, 78, 282-310.

Nottis, K. (2005). Supporting the mid-career researcher. The Journal of Faculty Development, 20(2), 95-98.

Perrewé, P. L., Hochwarter, W. A., Ferris, G. R., McAllister, C. P., Harris, J. N. (2014). Developing a passion for work passion: Future directions on an emerging construct. Journal of Organizational Behavior, $35,145-150$. 
Pololi, L. H., Evans, A. T. (2015). Group peer mentoring: An answer to the faculty mentoring problem? Journal of Continuing Education in the Health Professions, 35, 192-200.

Rittel, H. W., Webber, M. M. (1973). Dilemmas in a general theory of planning. Policy Sciences, 4, 155-169.

Strage, A., Merdinger, J. (2015). Professional growth and renewal for mid-career faculty. The Journal of Faculty Development, 29(1), 41-50.

Stubbs, B., Krueger, P., White, D., Meaney, C., Kwong, J., Antao, V. (2016). Mentorship perceptions and experiences among academic family medicine faculty: Findings from a quantitative, comprehensive work life and leadership survey. Canadian Family Physician, 62, e531-e539.

Tourangeau, A. E., Wong, M., Saari, M., Patterson, E. (2015). Generation-specific incentives and disincentives for nurse faculty to remain employed. Journal of Advanced Nursing, 71, 1019-1031.

Vemuri, P., Lesnick, T. G., Przybelski, S. A., Machulda, M., Knopman, D. S., Mielke, M. M., .. Petersen, R. C. (2014). Association of lifetime intellectual enrichment with cognitive decline in the older population. JAMA Neurology, 71, 1017-1024.

Ward, K. (2003). Faculty service roles and the scholarship of engagement. San Francisco, CA: Jossey-Bass. Wilson, R. (2012, June 3). Why are associate professors so unhappy? The Chronicle of Higher Education. Retrieved from http://www.chronicle.com/article/Why-Are-Associate-Professors/132071/

Yedidia, M. J., Chou, J., Brownlee, S., Flynn, L., Tanner, C. A. (2014). Association of faculty perceptions of work-life with emotional exhaustion and intent to leave academic nursing: Report on a national survey of nurse faculty. Journal of Nursing Education, 53, 569-579. 